\title{
Correction to: Red Earth, Green Glass, and Compositional Data: A New Procedure for Solid-State Elemental Characterization, Source Discrimination, and Provenience Analysis of Ochres
}

\author{
Andrew M. Zipkin ${ }^{1,2}$ • Stanley H. Ambrose ${ }^{1} \cdot$ Craig C. Lundstrom $^{3}$. \\ Gideon Bartov ${ }^{3}$. Alyssa Dwyer ${ }^{4}$. Alexander H. Taylor ${ }^{3}$
}

Published online: 9 March 2020

(C) Springer Science+Business Media, LLC, part of Springer Nature 2020

\section{Correction to: Journal of Archaeological Method and Theory (2020)} https://doi.org/10.1007/s10816-020-09448-9

The Online First version of this article unfortunately contained an error in the dimensions of LiBo fused bead shards described in the section "Lithium Borate Fusion Methods". On p. 13 of the manuscript PDF, in the sentence "Shards were generally selected based on size and shape: shards 0.5 to $1 \mathrm{~mm}$ in maximum dimension and exhibiting a flat surface were chosen." - the correct dimensions should be $\mathbf{1 . 0}$ to $\mathbf{5 . 0} \mathbf{~ m m}$.

The original article has been corrected.

Publisher's Note Springer Nature remains neutral with regard to jurisdictional claims in published maps and institutional affiliations.

The online version of the original article can be found at https://doi.org/10.1007/s10816-020-09448-9

Andrew M. Zipkin

andrew.zipkin@asu.edu

1 Department of Anthropology, University of Illinois at Urbana-Champaign, 109 Davenport Hall, 607 S. Mathews Ave, Urbana, IL 61801, USA

2 School of Human Evolution and Social Change, Arizona State University, P.O. Box 872402, Tempe, AZ 85287-2402, USA

3 Department of Geology, University of Illinois at Urbana-Champaign, 3086 Natural History Building, 1301 West Green Street, Urbana, IL 61801, USA

4 Department of Chemistry, University of Illinois at Urbana-Champaign, 505 S. Mathews Avenue, Urbana, IL 61801, USA 